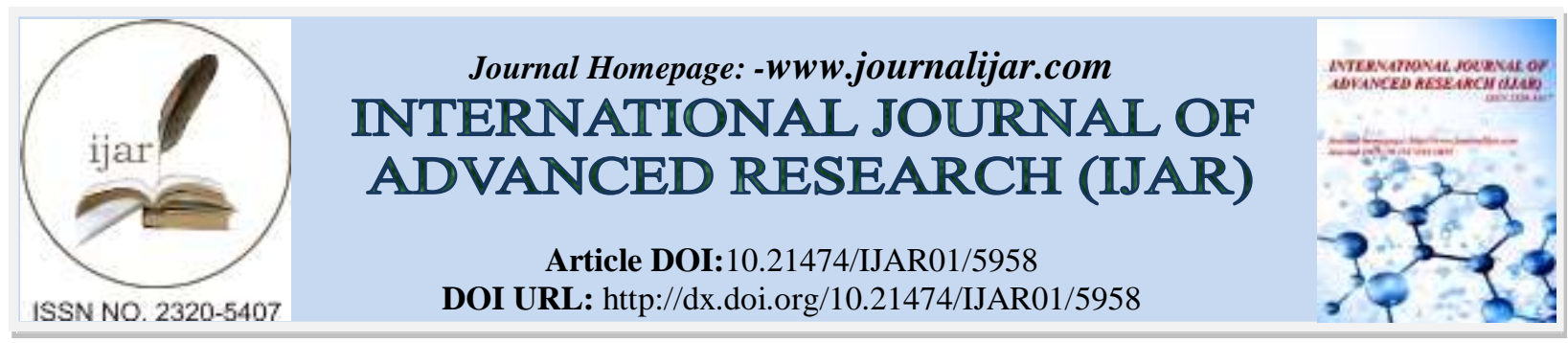

RESEARCH ARTICLE

\title{
URINARY TRACT INFECTION IN DIABETIC PATIENTS COMPARED WITH NON-DIABETICS: DIFFERENCE IN EPIDEMIOLOGY, MICROBIOLOGY AND CLINICAL FEATURES.
}

Kadhim A. Al-Hilali.

Assistant Professor Al-Safwa University College, Karbala, Iraq.

\section{Manuscript Info}

Manuscript History

Received: 03 October 2017

Final Accepted: 05 November 2017

Published: December 2017

Key words:-

Diabetes Mellitus type- two, Urinary

Tract Infection, UTI epidemiology, UTI microbiology, UTI clinical features.

\section{Abstract}

Background: Urinary Tract Infections (UTI) are considered as the most common bacterial infections in the outpatient practice and affect all age groups with female to male predominance.

Objective: The aim of the study was to investigate the epidemiological, bacteriological and clinical features of the urinary tract infection in diabetic patients and compare them with those of non-diabetics.

Patients and methods: Two groups of patients were included in the study. Group (1): people with Diabetes Mellitus, type-two, and Group (2): non-diabetic patients for comparison purpose. The diabetic group included (162) patients (81 females and 81 males). On the other hand Group (2) included (54) individuals (27 females and 27 males). The existence of the UTI was looked for in both samples searching for any difference relating to incidence, microbiology and clinical features. The recorded data were subjected to statistical evaluation.

Results: There were both some similarities as well as differences between the two groups of the investigated individuals in terms of incidence, bacteriology and clinical feature.

Conclusion: There were but no major differences in the epidemiology, microbiology and clinical features in the two groups. Some of the differences were significant whereas others lacked statistical significance.

Copy Right, IJAR, 2017,. All rights reserved.

\section{Introduction:-}

In health, bacterial colonization is confined to the lower end of the urethra and the remainder of urinary tract is sterile. Urinary tract infection (UTI) is characterized by colonization of the urinary tract by uropathogens at any level above the lower end of the urethra. Involvement of the bladder, urethra and prostate cause lower urinary tract infection and presented by dysuria, urgency, strangury and frequency. When kidneys are involved, systemic symptoms may be observed such as fever, rigor and pain and tender costo-phreni angle (Goddard et al., 2010).

The urine may contain pus (pyuria) with turbid appearance and unpleasant smell. Pyuria is the presence of (6-10) or more neutrophils per high power field (HPF) of unspun freshly voided mid-stream urine (Wikipedia the free Encyclopedia, Pyuria. Available at https://en.wikipedia.org/wiki/pyuria). It is considered as a sign of bacterial UTI. Exception to this rule is the presence of white cells under high power microscopic field (HPF), but on culturing 
techniques the result is a sterile culture. This is called sterile pyuria, examples are urinary tract tuberculosis, viruses, sexually transmitted diseases such as gonorrhea and other causes (Cumming, 2005; Wise and Schlegel, 2015).

UTI is the most common bacterial infection managed in general medical practice and accounts for 1-3\% of consultations. It is most common in women and $50 \%$ of them have (UTI) at some time, while it is uncommon in males except during the first year of life and after the age of 60 because of prostatic hypertrophy (Goddard et al., 2010).

Prevalence of UTI in women is (3-10.8\%) at the age of (18-20) and increased by about $1 \%$ each subsequent decade because of their short urethra, the trauma caused by sexual intercourse and the absence of bactericidal prostatic secretions. Urinary Tract Infection may present with symptoms (symptomatic UTI) or discovered during routine medical examination with no symptoms in spite of significant bacteruria. Asymptomatic bacteruria or untreated UTI can lead to damage of the urinary tract, leading to end-stage renal failure (ESRF) and dialysis. There is controversy in treating asymptomatic bacteruria, but most authorities accept the opinion that pregnant women, infants and cases suffering asymptomatic urinary treat abnormalities should be treated (Foxman et al. 2000).

Transmission of bacteria into the urinary is most often via the ascending transurethral route, but sometime by blood stream, lymphatics or vesico-colic fistula (Yaqoob, 2009). According to a multi health centers study, the most common etiological pathogen causing UTI is Escherichia coli, the next three pathogens were Enterococcus fecalis, Klebsiella species and Proteus mirabilis (Farrell et al. 2003).

Financially, the cost of handling the UTI within the community is significantly high (Foxman, 2010). After catheterization, special prevention and management measurements are needed (Hooton et al., 2010).

Diagnosis is arrived at if symptoms and signs of UTI are present plus some white blood cells in the urine beside a small number of microorganisms. However, in asymptomatic UTI there should be a significant number of microorganisms ( $>10^{5}$ microorganisms $/ \mathrm{ml}$ of urine). It is worthwhile to point out that Urinary Tract Infections are generally self-limiting but have the propensity to recur (Foxman, 2010).

\section{Patients and Methods:-}

The study was a prospective one conducted on patients visiting private medical clinics and diabetic clinic of AlHussein Medical City Teaching Hospital, Karbala, during the period from the $1^{\text {st }}$ of June, 2016 to the $31^{\text {st }}$ of May, 2017. It covered (162) Diabetes Mellitus type-two patients proved previously during regular clinical visits. They were (81) females and (81) males. They were assigned to Group-1. Another group of patients, Group-2, included (54) nondiabetic patients: (27) females and (27) males. The recorded data included: age, sex duration of diabetes, symptoms in addition to other information came out by clinical examination. Each patient was provided with a sterile container to collect freshly voided mid-stream urine sample according to guide lines of asepsis. A blood sample was also taken for complete blood picture, serumcreatinin, urea and $\mathrm{HbA1C}$.

Portion of the collected urine was centrifuged and subjected to microscopic examination. The presence of neutrophils (> 6-10 / HPF) was considered significant. Another portion was used for culture. The collected data were analyzed and statistically evaluated.

\section{Results:-}

The mean age of the diabetic patients was $58 \pm 12$ and of non-diabetics $57 \pm 13$ years. The duration of diabetes ranged between 8 months and 15 years with a mean of $7 \pm 6.5$ years. Tables (1) and (2) show age and sex distribution of the diabetic group (Group-1) and the non-diabetic group (Group-2, control group). Distribution of the number of patients with UTI in the two groups are presented in Table (3). Table (4), (5) and (6) present results of the microscopic and culture observations of both diabetic and non-diabetic patients. Observed symptoms in patients of both groups are displayed in Tables (7) and (8). Table (9) shows comparison of the incidence of microorganisms causing UTI in diabetics and non-diabetic patients. .

\section{Discussion:-}

Data of the present investigation revealed that UTI was encountered in male and female diabetic (Table 1) and nondiabetic (Table 2) patients of the age range subgroups. Females and males, regardless their age, were closely 
susceptible and there was non-significant correlation between UTI prevalence and sex or age. Bonadioet al. (1999) reported that UTI in diabetic patients was a common scenario in nephrology outpatient clinics and encountered among all age groups and both sexes with female predominance.

Urinary tract infection occurred more frequently in diabetic patients than in the general population with a relative risk ranging from $1.5-4.0$. The real cause was unknown but hyperglycemia, immunodeficiency, modified urothelium and chronic neurologic bladder dysfunction could be blamed (Tourretet al., 2014). Results of the present study pointed out to this fact. Sixty six out of (162) diabetic patients (i.e. $40.7 \%$ ) suffered UTI, whereas (18) individuals caught UTI out of $(54)$ non-diabetic patients $(33.3 \%)$. The difference was significant ( $\mathrm{p}$ value $<0.01$ ). Possibility of complications associated with UTI in diabetic patients has been documented (Mnifet al., 2013).

There was a closed correlation between urine microscopy and urine culture results (Tables 4, 5 and 6). Increased number of neutrophilic leukocytes under high power field was accompanied with increased possibility of positive culture. Usually cases of UTI in diabetic patients were only bacteruria positive which was a serious sign because bacteruria might lead to renal damage in a silent way. Its occurrence was usually more common in diabetics than in non-diabetics due to combination of host and local causes (Aswani et al., 2014).

Asymptomatic UTI was predominant in diabetic patients (83\%) as presented in Table (7), whereas all (100\%) of the non-diabetic patients did not show symptoms (Table 8). Seventeen percent of the individuals of the diabetic group showed symptomatic UTI (Table 7). On the other hand, none of the non-diabetic patients showed symptomatic UTI (Table 8). Incidence of cystitis and pyelonephritis were more common in diabetics with frequent isolation of resistant bacteria (Nicolle, 2005). Emphysematous pyelonephritis, pyelitis, cystitis beside renal abcesses and renal papillary necrosis were not uncommon complications associated with diabetes mellitus (Mnifet al., 2013).

Table (9) presents comparisons in incidence of specific uropathogens in the diabetic and non-diabetic UTI patients of this investigation. Non significant differences have been observed between number of infected patients of the diabetic group and non-diabetic group. Infection with E. coli has been recorded at high rates in both groups. Lower rates of incidence have been noticed for Pseudomonas species, Klebsiella species, Enterococci and Proteusmirabilis. Significant differences have been recorded for Staphylococcussaprophyticus and Streptococcusfecalis. Cases with Staphylococci have been significantly $(\mathrm{p}<0.01)$ more observed in non-diabetic group as compared with the cases of the diabetics. On the contrary, Streptococcusfecalis was isolated from four diabetics, whereas this microorganism did not establish itself in any of the non-diabetic UTI patients $(\mathrm{p}<0.05)$. Asymptomatic fungal infections may occur in diabetic patients and should be ruled out during their visit to the outpatient clinics (Kremeryet al. 1999). Ronald (2003) came out with findings that etiologic pathogens associated with UTI among diabetics were predominantly $E$. coli $(80 \%)$ followed by less incident microorganisms includingKlebsiela spp. Strept. fecalis and Enterococci have more incidence in diabetic UTI patients than in non-diabetic population. Variations in the established microorganism species within the urinary tract, or emergence of resistance, included improper duration of antibiotic treatment (Bonadio et al., 1999), catheterization, spinal cord injuries as well as immunologic and metabolic disorders (Ronald, 2003). Bonadioet al. (1999) reported that the epidemiological, bacteriological and clinical features of diabetic and non-diabetic groups of UTI Italian patients did not show statistically significant differences (Table 10). Furthermore, their results revealed that the asymptomatic cases among diabetic UTI patients were more predominant as compared with the corresponding non-diabetic UTI individuals. A clinical trial involved Australian groups of patients recorded isolation of several species of microorganisms from urine samples of diabetic and non-diabetic UTI cases (Table 11). The authors pointed out to a significant difference in the incidence of the Pseudomonas only $(\mathrm{P}<0.05)$.

Table 1:-Age and sex distribution in the diabetic group of patients.

\begin{tabular}{|c|c|c|c|}
\hline $\begin{array}{c}\text { Age Subgroups } \\
\text { in years }\end{array}$ & Male & Female & Total Number \\
\hline $\mathbf{4 2 - 5 0}$ & 27 & 29 & 56 \\
\hline $\mathbf{5 1 - 6 0}$ & 26 & 25 & 51 \\
\hline $\mathbf{6 1 - 7 0}$ & 28 & 27 & 55 \\
\hline Total & 81 & 81 & 162 \\
\hline
\end{tabular}

Table 2:-Age and sex distribution in the control group of patients.

\begin{tabular}{|c|c|c|c|}
\hline $\begin{array}{c}\text { Age groups } \\
\text { in years }\end{array}$ & Male & Female & Total Number \\
\hline
\end{tabular}




\begin{tabular}{|c|c|c|c|}
\hline $\mathbf{4 2 - 5 0}$ & 8 & 10 & 18 \\
\hline $\mathbf{5 1 - 6 0}$ & 9 & 8 & 17 \\
\hline $\mathbf{6 1 - 7 0}$ & 10 & 9 & 19 \\
\hline Total & 27 & 27 & 54 \\
\hline
\end{tabular}

Table 3:-Number of patients with UTI in the two groups of patients.

\begin{tabular}{|c|c|c|c|c|c|c|}
\hline Group & Gender & Number & $\begin{array}{c}\text { Total Number } \\
\text { of Patients }\end{array}$ & $\begin{array}{c}\text { Number } \\
\text { of Patients with } \\
\text { UTI }\end{array}$ & $\begin{array}{c}\text { Total } \\
\text { Number } \\
\text { of Patients }\end{array}$ & $\begin{array}{c}\% \\
\text { of } \\
\text { Total }\end{array}$ \\
\hline \multirow[t]{2}{*}{ Diabetic } & Male & 81 & \multirow[t]{2}{*}{162} & 28 & \multirow[t]{2}{*}{$66^{\dagger}$} & \multirow[t]{2}{*}{$40.7 \%$} \\
\hline & Female & 81 & & 38 & & \\
\hline \multirow[t]{2}{*}{ Non-Diabetic } & Male & 27 & \multirow[t]{2}{*}{54} & 6 & \multirow[t]{2}{*}{18} & \multirow[t]{2}{*}{$33 \%$} \\
\hline & Female & 27 & & 12 & & \\
\hline
\end{tabular}

$\mathrm{P}$ value $:<0.01$

Table 4:-Microscopic and culture results of urine in UTI diabetic males $(\mathrm{n}=81)$ Positive culture $=>10^{5}$ microorganisms /ml urine.

\begin{tabular}{|c|c|c|}
\hline $\begin{array}{c}\text { No. of } \\
\text { Patients }\end{array}$ & $\begin{array}{c}\text { Microscopic Results: No. of } \\
\text { Neutrophils per High Power } \\
\text { Field (HPF) }\end{array}$ & $\begin{array}{c}\text { No. of Positive } \\
\text { Cultures }\end{array}$ \\
\hline 27 & $1-2$ & Nil \\
\hline 26 & $3-6$ & 2 \\
\hline 28 & $>8-10$ & 26 \\
\hline
\end{tabular}

Table 5:-Microscopic and culture results of urine in UTI diabetic females $(\mathrm{n}=81)$. Positive culture $=>10^{5}$ microorganisms /ml urine.

\begin{tabular}{|c|c|c|}
\hline $\begin{array}{c}\text { No. of } \\
\text { Patients }\end{array}$ & $\begin{array}{c}\text { Microscopic Results: No. of } \\
\text { Neutrophils Per High Power } \\
\text { Field (HPF) }\end{array}$ & $\begin{array}{c}\text { No. of Positive } \\
\text { Cultures }\end{array}$ \\
\hline 15 & $2-4$ & Nil \\
\hline 28 & $6-8$ & 4 \\
\hline 38 & $>10-12$ & 34 \\
\hline
\end{tabular}

Table 6:-Microscopic and culture results of urine in non-diabetic UTI patients.

\begin{tabular}{|c|c|c|c|}
\hline Gender & $\begin{array}{c}\text { No. of UTI } \\
\text { patients }\end{array}$ & $\begin{array}{c}\text { Microscopic Results: No. of } \\
\text { Neutrophils } \\
\text { Per/ HPF }\end{array}$ & Cultures results \\
\hline Male & 6 & $6-10$ & Positive \\
\hline Female & 1 & $2-4$ & Positive \\
\hline Female & 2 & $6-10$ & Positive \\
\hline Female & 9 & $>10-12$ & Positive \\
\hline Total & 18 out of 54 & & \\
\hline
\end{tabular}

Table 7:-Symptomatic and asymptomatic UTI diabetic patients.

\begin{tabular}{|c|c|c|c|c|}
\hline Clinical Signs & Male & Female & Total & Percentage \\
\hline Symptomatic & 3 & 8 & 11 & $17 \%$ \\
\hline Asymptomatic & 25 & 30 & 55 & $83 \%$ \\
\hline Total & 28 & 38 & 66 & $100 \%$ \\
\hline
\end{tabular}

Table 8:-Symptomatic and asymptomatic UTI non-diabetic patients.

\begin{tabular}{|c|c|c|c|c|}
\hline Signs and symptoms & Male & Female & total & Percentage \\
\hline Symptomatic & $\mathbf{0}$ & $\mathbf{0}$ & $\mathbf{0}$ & $\mathbf{0}$ \\
\hline Asymptomatic & 6 & 12 & 18 & $100 \%$ \\
\hline
\end{tabular}


Table 9:-Comparison of incidence of organisms causing UTI in diabetic patients versus non-diabetic patients.

\begin{tabular}{|c|c|c|c|}
\hline Micro- organism & $\begin{array}{c}\text { Incidence in Diabetic } \\
\text { Patients }\end{array}$ & $\begin{array}{c}\text { Incidence in Non-Diabetic } \\
\text { Patients }\end{array}$ & P Value \\
\hline E. coli & 76 & 78 & N/S \\
\hline Staphylococcus saprophyticus. & 2 & 8 & $<0.01$ \\
\hline Pseudomonas spp. & 6 & 5 & N/S \\
\hline Klebsiella spp. & 5 & 4 & N/S \\
\hline Enterococcus & 4 & 3 & N/S \\
\hline Proteus mirabilis & 3 & 2 & $<0.0 .5$ \\
\hline Strept. fecalis & 4 & 0 & \\
\hline
\end{tabular}

Table 10:-Comparison of incidence of micro-organisms (uropathogens) in Italian diabetic and non-diabetic UTI patients (Bonadio et al. 1999).

\begin{tabular}{|c|c|c|}
\hline Name of the Micro-organism (uropathogen) & Incidence in Diabetic Patients & Incidence in Non-Diabetic Patients \\
\hline E. coli & 56.1 & 56.8 \\
\hline Proteus spp & 7.9 & 7.2 \\
\hline Pseudomonas spp & 6.7 & 8.2 \\
\hline Enterococcus fecalis Central cecum spp & 6.7 & 7.2 \\
\hline
\end{tabular}

Statistical analysis showed non-significant differences.

Table 11:-Micro-organisms isolated from urine cultures of Australian diabetic and non-diabetic UTI patients. (Aswani et al., 2014).

\begin{tabular}{|c|c|c|c|}
\hline Micro- organism & Diabetic & Non Diabetic & P value \\
\hline E. coli & 117 & 73 & N/S \\
\hline Klebsiella & 22 & 18 & N/S \\
\hline Enterococcus & 18 & 10 & N/S \\
\hline Pseuodomonas & 3 & 15 & \\
\hline Acinetobacter & 3 & 0 & \\
\hline Citrobacter & 3 & 2 & \\
\hline Proteus & 3 & 1 & \\
\hline Coag. Neg. Staph & 3 & 4 & \\
\hline Coag. Posit. Staph & 4 & 1 & \\
\hline Candida & 5 & 0 & \\
\hline
\end{tabular}

\section{References:-}

1. Aswani, S.M., Chandrashekar, U.K., Shivashankara, K.N. and Pruthvi, B.C. (2014): Clinical profile of urinary tract infections in diabetics and non-diabetics. Australasian Med. J., 7(1): 29-34.

2. Bonadio, M., Meini, M., Gigli, C., Longo, B. and Vigna, A. (1999): Urinary tract infection in diabetic patients. UrologiaInternationalis, 63: 215-219.

3. Cumming, A. (2005): The renal system. In: Macleod's clinical examination. Eleventh edition, Edinburgh, Churchill Livingstone, p:194.

4. Farrell, D. J., Morissey, L., De Rubeis, D., Robbins, M. and Flemingham, D. (2003): A UK Multi centre study of the antimicrobial susceptibility of bacterial pathogens causing urinary tract infection. J. Infection., 46(2): 94-100.

5. Foxman, B., Barlow, R., D'Arcy, H., Gillespie, B. and Sobel, J.D. (2000) Urinary tract infection: Self- reported incidence and associated costs. Annals of Epidemiology. 10 (8): 509 -515.

6. Foxman, B. (2010): The epidemiology of urinary tract infection. Nature Reviews Urology, 7: 653- 660.

7. Goddard, J., Turner, A.N. and Stewart, L.H. (2010): Urinary tract infection. In: Colledge, N. R., Walker, B.R. and Ralston, S. H.: Davidson's Principles and Practice of Medicine 21st edition, Edinburgh, Churchill Livingstone. pp:469-472.

8. Hooton, T.M., Bradley, S.F., Cardenas, D.D., Colgan, R., Geerlings, S.E., Rice, J.C., Saint, S., Schaeffer, A.J., Tambayh, P.A., Tenke, P. and Nicolle, L.E. (2010) Diagnosis, prevention and treatment of catheter-associated urinary tract infection in adults: 2009 International Clinical Practice Guidelines from the Infectious Diseases Society of America. Clin. Infect. Dis., 50: 625 - 663. 
9. Kremery, S., Dubrava, M., Kremery, V. Jr. (1999): Fungal urinary tract infection in patients at risk. Int. J. Antimicrob. Agents, 11: $289-291$.

10. Mnif, M.F., Naceur, B.N., Rekik, N., Mnif, M.A., Kamoun, M., Kacem, F.H., Bouaziz, Z. and Charfi, N. (2013): Complicated urinary tract infections associated with diabetes mellitus: Pathogenesis, diagnosis and management. Indian J. Endocrinol. Metab., 17 (3): $442-445$.

11. Nicolle, L. E. (2005): Urinary tract infection in diabetes. Current Opinion in Infectious Diseases, 18: $49-53$.

12. Ronald, A. (2003): The Etiology of urinary tract infection: Traditional and emerging pathogens. Disease-aMonth, 49 (2): $71-82$.

13. Tourret, J., Bagnis, C.I. and Denamur, E. (2014): Urinary tract infection in diabetic patients. La Revue du Praticien, 64 (7): $980-983$.

14. Wise, G.J. and Sehlegel, P.N. (2015): Sterile pyuria. New Eng. J. Med., 372 (11): 1048 - 1054.

15. Yaqoob, M.M. (2009): Urinary tract infection. In: Kumar, P. and Clark, M. C., Kumar and Clark Clinical Medicine, 7th edition, Edinburgh, Saunders, pp 599-603. 